\title{
Prática freelancer em design: os efeitos da falta de formalização na prestação de serviços
}

\author{
Freelance design practice: the \\ effects of the lack of formalization \\ in service providing
}

\author{
Letícia Bento dos Santos $^{[1]}$, Patrícia Lopes Damasceno ${ }^{[2]}$
}

\begin{abstract}
Resumo: Este artigo apresenta uma pesquisa acerca do profissional freelancer em design em um contexto local, a qual foi realizada como parte de um Trabalho de Conclusão de Curso defendido junto ao curso de Design Digital da Universidade Federal de Pelotas. Isso posto, discute-se aqui a prática profissional freelancer em design através de pesquisa bibliográfica e documental, a fim de compreender certos aspectos característicos do freelancer brasileiro. Em seguida, apresenta-se algumas das problemáticas encontradas por eles frente à precarização do trabalho e falta de formalização contratual. Posteriormente, expõe-se os dados obtidos por meio da aplicação de um questionário direcionado a designers locais e, por fim, propõe-se um modelo de termo de compromisso como principal resultado da pesquisa empreendida.
\end{abstract}

Palavras-chave: Freelancer; Design; Prática profissional; Prestação de serviços; Termo de compromisso.

Abstract: This article presents and discusses the practice of freelance design in Brazil through a research which was conducted by a Digital Design graduate in December 2019. That being said, we discuss the professional freelance practice of design through bibliographical research and documentary research, in order to understand certain characteristic aspects of the average Brazilian freelancer. Furthermore, we discuss

[1] Bacharel em Design Digital, UFPEL. le.ticicrist@gmail.com

[2] Doutora em Comunicação e Informação, UFPEL. pldamasceno@gmail.com 
some of the main difficulties encountered by these workers in the face of lack of a contractual agreement stemming from the precarization of freelance practice. These difficulties were verified through the data and testimonies obtained through a questionnaire directed to local designers, which presented questions regarding their experience as freelance designers.

Keywords: Freelancer. Design. Professional practice. Service Providing. Contract.

\section{INTRODUÇÃO}

Este artigo tem por propósito apresentar uma síntese da pesquisa desenvolvida como Trabalho de Conclusão de Curso realizado junto ao curso de Design Digital da Universidade Federal de Pelotas em dezembro de 2019. O referido trabalho teve como intuito principal o desenvolvimento de uma ferramenta que auxiliasse designers freelancers, sobretudo iniciantes, a protegerem sua prática de complicações oriundas da falta de um documento que formalizasse a relação de trabalho. Como base para a consecução desse projeto, fez-se necessária a compreensão teórica da prática freelancer de design no Brasil e os efeitos da falta da formalização contratual na experiência como profissional autônomo. Contudo, o entendimento desta conjuntura se mostrou relevante não apenas no âmbito do objetivo pretendido, mas também como um importante questionamento acerca da prática profissional de design no Brasil.

De acordo com uma reportagem publicada no portal G1 em 2015, a crescente taxa de desemprego que assolava o mercado de trabalho nacional contribuiu para um aumento de $33 \%$ (no período de um ano) na quantidade de profissionais de tecnologia que trabalhavam por conta própria naquele ano (BIAZZI; LUQUET, 2015, on-line). Ainda de acordo com a reportagem, desses profissionais, 35\% eram designers. Atualmente, a pandemia por Covid-19 e as respectivas medidas de distanciamento social remodelaram as dinâmicas de trabalho, seja através da imposição da prática remota ou da propulsão da taxa de desemprego, proveniente das demissões em massa observadas nos mais variados ramos de atuação (LANDOLFl; BERNARDO, 2020). Estes fatores compeliram a multiplicação de profissionais que atuam remotamente em 
2020, sobretudo de forma autônoma, como aponta um levantamento realizado pela plataforma Workana ${ }^{[3]}$.

Tendo em vista este cenário, neste estudo será abordada a natureza da prática autônoma de design no Brasil, tendo por base a pesquisa bibliográfica e documental, na qual se analisou dados demográficos obtidos em um levantamento realizado pela empresa de marketing Rock Content ${ }^{[4]}$ em 2019. Nesta pesquisa, foi possível verificar algumas das principais características do profissional freelancer brasileiro médio, como renda mensal e tempo de carreira, e inferir como estes fatores podem influenciar a abdicação de um documento que formalize a relação entre profissional e cliente. Em seguida, foram expostos algumas das principais formas de atuação freelancer, sendo on-line ou presencial e como se diferem.

Com o intuito de refinar os dados sobre a atuação freelancer, as possíveis necessidades e os problemas enfrentados por eles frente à prática informal, também foi aplicado um questionário que levantou dados qualitativos e quantitativos, com perguntas abertas e fechadas, veiculado on-line por meio da plataforma Jotform ${ }^{[5]}$ e divulgado em redes sociais que oferecessem comunidades que compreendessem designers freelancers. Através desta ferramenta, foi possível coletar informações e depoimentos de 56 designers freelancers de diferentes regiões do Rio Grande do Sul.

Na sequência, é discutida a formalização da relação de trabalho, muitas vezes concretizada por meio de um contrato, a fim de esclarecer o que constitui um documento de prestação de serviços e qual a sua finalidade em uma transação comercial, abordando a relação com o cliente e questões relativas à venda de serviços profissionais. Por fim, é proposto um modelo de termo de compromisso como resultado da investigação.

\section{O DESIGNER FREELANCER BRASILEIRO}

No Brasil, não há uma distinção clara entre os termos "autônomo" e "freelancer". No entanto, o uso da palavra freelancer tem ganhado popularidade para se referir à profissionais autôno-
[3] A Workana é uma plataforma que conecta freelancers clientes que precisam contratar profissionais de diferentes áreas para expandir suas empresas (WORKANA, 2020).

[4] A Rock Content é uma empresa de marketing com enfoque em produção de conteúdo.

[5] Jotform é uma plataforma online que permite a construção de formulários e coleta de dados. Disponível em: <https:// www.jotform.com/about/> 
mos os quais podem atuar nas áreas da comunicação, design e tecnologia da informação, entre outros (PINHEIRO, 2018).

Diante disso, conforme mencionado na introdução, os designers representam uma porção considerável do total de profissionais que atuam de forma autônoma no país, sendo o desemprego um elemento propulsor para a ascensão deste modelo de trabalho. Contudo, o desemprego não é o único fator contribuinte para este fenômeno. Ainda de acordo com a reportagem, outros fatores, como a necessidade de certas empresas em reduzir o número de funcionários e diante da flexibilidade proporcionada ao prestador de serviços pelo modelo autônomo, criaram um cenário propício para o surgimento de uma nova geração de profissionais independentes.

A nova geração, essa faixa dos 20 aos 30 anos, ela demanda também mais flexibilidade. Vai ser difícil para uma empresa conseguir reter esse profissional mais novo que ele já não quer aquela dependência da carteira assinada que tem com as empresas atualmente (BAIGES , 2015 apud BIAZZI; LUQUET, 2015, on-line).

Não obstante, as medidas de distanciamento social impostas como principal forma de contenção ao avanço do Covid-19, acarretou, conforme Landolfi e Bernardo (2020, on-line), em um "expressivo contingente de trabalhadores e trabalhadoras que desempenham as suas atividades laborais de forma remota". Essa característica se apresenta bastante presente na prática autônoma de design, uma vez que o designer, tendo como matéria-prima a informação, tem a possibilidade de estar presente em vários tipos de negócios e em diversas relações que se estabelecem entre as pessoas (STRUNCK, 2010).

A partir de uma síntese dos dados levantados em 2019 pela empresa Rock Content, por meio de sua varredura anual do mercado freelancer brasileiro, foi possível inferir algumas características que se mostram pertinentes para este estudo, pois podem apresentar uma justificativa para não utilização de um documento que formalize a relação com o cliente. 
A primeira característica observada é o tempo de atuação. De acordo com a pesquisa, o tempo de atuação médio no mercado freelancer informado pelos respondentes é curto, sendo o maior percentual referente ao período de 1 a 2 anos. A partir disso, cabe questionar se o tempo de profissão influencia na opção de obter ou não um meio de formalização contratual, já que o acúmulo de experiências negativas provenientes de possíveis desentendimentos com clientes poderia se tornar um fator determinante. Outro ponto contemplado pela pesquisa foi a renda mensal obtida pelos freelancers. Entre os entrevistados, 45,7\% ganha até um salário com a atividade independente, ou seja, um valor inferior a $\mathrm{R} \$ 998$, conforme o salário mínimo vigente em 2019. A renda reduzida pode ser outro fator influente na abstenção da formalização contratual, uma vez que pode limitar o valor que o profissional estaria disposto a investir em um auxílio jurídico para a redação de um documento que cumprisse esse papel.

Diante desses dados, fez-se necessária a abordagem das questões específicas inerentes ao designer freelancer. 0 avanço tecnológico e a popularização do trabalho freelancer oferecem aos profissionais diferentes opções de atuação, divulgação dos seus serviços e meios de compensação financeira. De um modo geral, trabalhadores freelancers trabalham de forma independente, utilizam sites e plataformas que facilitam o processo de obtenção de clientes ou são representados por um agente ou empresa que revende seus serviços para contratantes. No âmbito do presente artigo, é importante destacar os dois principais meios pelos quais os profissionais exercem suas atividades. O primeiro deles se manifesta através dos mercados de trabalho on-line, onde empresas podem terceirizar diversos tipos de serviços, reduzindo o corpo de funcionários e, ao mesmo tempo, logrando de mão-de-obra qualificada, que em um no passado recente estaria acessível apenas a corporações de grande porte (LAUBACHER; MALONE, 1998). 
De acordo com Hong e Pavlou (2013), existem dois tipos principais de mercados de trabalho on-line: o mercado de disputa, onde o profissional disponibiliza um produto já finalizado o qual receberá ofertas de valores de diversos compradores e o de oferta reversa. No modelo mais comum, o de oferta reversa, os profissionais só iniciam o processo de trabalho após a contratação por um cliente. Alguns exemplos desses modelos de mercado são as plataformas on-line freelancer.com, Fiverr e as brasileiras Workana e 99freelas.

Essas plataformas podem ser observadas como ambientes controlados, nos quais tanto profissional quanto contratante são amparados por funcionalidades e regras que resguardam a transação comercial. Uma vez que nelas estão presentes restrições a respeito do sistema de pagamento e de avaliação, bem como regras para compradores e freelancers em relação ao processo de venda, compra, pagamentos e prazos. Por este motivo, esses sites se mostram atrativos não apenas para àqueles que necessitam de serviços especializados, mas também para freelancers, sobretudo iniciantes, os quais ficam restritos aos termos de uso e funcionalidades da plataforma.

Ao analisarmos o contexto brasileiro, é possível associar o crescimento do trabalho freelancer ao cenário de desemprego em âmbito geral e, no caso da área do design, à falta de familiaridade com os serviços prestados, bem como a desvalorização desses profissionais em empresas de pequeno e até médio porte. Por esse motivo, é comum que designers se sintam impelidos a buscarem oportunidades em capitais ou cidades com maior movimentação econômica. Nesta perspectiva, o trabalho autônomo se mostra como uma forma de atuação em sua região de origem, prestando seus serviços a quem os solicite em âmbito local. Assim, é mais comum a prestação de serviços sem a mediação de plataformas como essas.

Embora a instabilidade seja uma característica inerente ao trabalho freelancer, a independência na prestação de serviços, sem alguma ferramenta de apoio, pode agravar este 
fenômeno, uma vez que o trabalhador fica responsável por todos os fatores que compõem a prestação do serviço. Essa instabilidade pode ser compreendida pela dificuldade em conseguir clientes e, desse modo, não obter um fluxo de renda consistente e constante, impactando na própria precarização da prestação de serviços. Em contrapartida, mesmo em uma situação favorável no que diz respeito à obtenção de clientes, o profissional freelancer muitas vezes fica à mercê de um pagamento reduzido em comparação com qualidade de seus serviços. Associado a isso, pode-se tomar como desvantagens a falta de acesso a seguridades como plano de saúde, licença maternidade, pensões em caso de doença e férias remuneradas. Trebor Scholz (2013, on-line., tradução livre) assume uma postura crítica em relação à essa modalidade de trabalho.

Estas são novas formas de trabalho, mas antigas formas de exploração. Não há salário mínimo ou seguro de saúde, e até agora os órgãos reguladores federais e estaduais não intervieram. O trabalho digital importa; tais ocupações mal remuneradas e assalariadas não devem ser ignoradas quando se pensa a respeito do capitalismo cognitivo.

Em um contexto onde o trabalho faz parte do dia-a-dia do indivíduo, a sua relação com o mesmo torna-se cada vez mais íntima e o senso de gratificação e validação pessoal passa a derivar mais do desempenho profissional. Segundo Gregg (2011), as novas tecnologias mudaram o nosso senso de disponibilidade e permitiram que o trabalho invadisse espaços e momentos que, outrora, seriam dedicados a outras atividades. Este fenômeno propicia um cenário no qual esforços e sacrifícios realizados pelo profissional não são necessariamente valorizados ou reconhecidos pelo empregador. Em uma modalidade de trabalho instável com um tempo de atividade estendido, fica difícil mensurar em uma folha de ponto ou planilha, assim o balanço entre "vida e trabalho" desequilibra-se.

Nesta conjuntura, é também interessante mencionar a atividade profissional feminina. De acordo com a pesquisa realizada pela Rock Content, as mulheres representam, se não 
a maioria, uma grande parte dos freelancers brasileiros. Conforme Gregg (2011), o trabalho freelancer mostra-se como um modo de evitar a falta de flexibilidade presencial característica do trabalho formal, considerando que a carga do trabalho doméstico ainda é muitas vezes atribuída à mulher. Por esse motivo, muitas mulheres acabam por recorrer ao home-office numa tentativa de conciliar o período de trabalho remunerado com a jornada doméstica.

Os capítulos subsequentes mostram que as mulheres se preparam para esperar até que as tarefas de limpeza e cozinha estejam concluídas, e o resto da casa esteja dormindo, para ter tempo sozinha, dedicado ao trabalho. O tempo sozinha com o trabalho remunerado pode servir de consolo, uma vez que o trabalho doméstico não é reconhecido. (GREGG, 2011, p.5, tradução livre)

Em suma, a precarização do trabalho freelancer manifesta-se por diversos aspectos e é um elemento importante a ser considerado ao discutir a instabilidade intrínseca à esta modalidade de atuação. Seja em relação à precificação injusta ou à falta de mensuração e controle do tempo dedicado à atividade. No item seguinte serão discutidos, com o auxílio dos dados coletados pelo questionário, outros aspectos da prática freelancer em contexto local e o modo como estes se relacionam com a discussão proposta pelo presente artigo.

\section{A ATUAÇÃO DO DESIGNER FREELANCER EM UM CONTEXTO LOCAL}

No presente tópico serão expostos os dados coletados por intermédio do estudo exploratório realizado, bem como as questões levantadas aos respondentes e seus depoimentos acerca de suas experiências pessoais como designers freelancers.

O questionário ficou disponível para preenchimento no decorrer de nove dias ${ }^{[6]}$, ao longo dos quais foi possível obter 56 respostas. A partir da primeira pergunta "atua ou já atuou como designer freelancer?" verificou-se que $61 \%$ atuam como

[6] O questionário ficou aberto para respostas entre os dias 24/10/2019 e 01/11/2019. freelancers enquanto $29 \%$ já atuaram. 
As áreas de formação mais proeminentes foram as de design gráfico (44\%) e design digital (30\%). Os profissionais autodidatas representaram $8 \%$ dos respondentes. Foram ainda oferecidas opções de formações não pertencentes à área do Design - jornalismo e publicidade e propaganda —, as quais representaram $7 \%$ das respostas. Este resultado também pode ter sido impactado pela grande circulação do questionário entre os acadêmicos da UFPel, a qual oferece, na área do Design, as habilitações gráfico e digital, além de graduação em jornalismo. Além disso, parte dos respondentes podem ser oriundos do Instituto Federal Sul-rio Grandense (IFsul), o qual oferece um curso de graduação em Design. Considerando estes fatores, não é de se surpreender o fato de que $41 \%$ dos respondentes são estudantes. Em segundo e terceiro e quarto grau de proeminência, estão, respectivamente, os graduados há mais de 2 anos (21\%), graduados há mais de 6 anos (16\%) e recém-graduados, há menos de 2 anos (8\%). Entende-se então, a partir destes dados, que uma quantidade considerável de profissionais concilia a sua prática freelancer com as suas obrigações acadêmicas. Contudo, as obrigações acadêmicas não são o único fator a ser conciliado com a atividade profissional freelancer. Embora 33\% dos respondentes afirmarem dedicação exclusiva à atividade freelancer, $42 \%$ declaram atuar como colaboradores em empresas em paralelo. Tal conclusão torna-se notória ao considerarmos que, em virtude do acúmulo de funções experienciado por esses profissionais, é necessário o estabelecimento de prioridades em relação ao tempo dedicado a cada uma delas. O trabalho freelancer compete, então, com o trabalho formal e a atividade acadêmica, atividades as quais, por natureza, ocupam um tempo fixo e extenso na rotina de quem se dedica a elas. Este cenário pode favorecer uma certa negligência no que diz respeito às atividades de planejamento e preparação, importantes para o sucesso profissional freelancer (GASPARINI, 2017). Considerando que a redação de um termo de compromisso envolve etapas de pesquisa, plane- 
jamento e execução, é natural que, nessas circunstâncias, o profissional opte por deixar este processo em segundo plano, sem refletir o suficiente para compreender sua necessidade e consequente confecção.

Em relação ao tempo de atuação, os dados recolhidos apontam que a maioria dos respondentes é iniciante ou intermediário, uma vez que $37 \%$ atua há $1-3$ anos e $25 \%$ atua há menos de 1 ano. Respondentes que atuam há 4-6 anos representam $14 \%$ da amostra, enquanto os que atuam há 7 anos ou mais representam $21 \%$.

Outro ponto levantado foi a média de clientes anual desses profissionais, na qual $51 \%$ dos respondentes obtêm uma média de 1 a 4 clientes anualmente, enquanto $26 \%$ obtêm 5 a 10 clientes. Além disso, $17 \%$ obtém 10 a 20 clientes ou mais. Pode-se interpretar estes dados, no mínimo, de duas maneiras: a) ao observarmos que a maioria dos respondentes obtêm uma média de 1 a 4 clientes anualmente, desconsiderando circunstâncias desconhecidas à esta pesquisa, é seguro entender em um primeiro momento que ao menos uma parcela desses profissionais encontra dificuldades em conquistar clientes; b) no entanto, é importante considerar que, ao somarmos os profissionais que obtêm 5 a 10 aos que obtêm 10 a 20 , encontramos um total de $43 \%$ de profissionais que atendem uma quantidade satisfatória de clientes anualmente.

Diante disso, nota-se claramente uma discrepância ao considerarmos o próximo ponto: a média de renda mensal. Dos respondentes, 39\% declararam obter um valor inferior a um salário mínimo mensalmente, enquanto $17 \%$ obtêm de 1 a 2 salários mínimos. Considerando que $43 \%$ dos respondentes atingem uma média satisfatória de clientes anualmente, é possível inferir que os valores cobrados pelos serviços de uma parte considerável destes profissionais são baixos. Conforme o cruzamento dos dados de renda e média de clientes recoIhidos, foi verificado que $21 \%$ dos respondentes obtém uma quantidade satisfatória de clientes anual e ao mesmo tempo obtém uma renda máxima de 2 salários mínimos - sendo 
algumas inferiores a 1 salário mínimo. A partir destas considerações, questiona-se aqui o motivo pelo qual esses profissionais obtêm uma renda tão reduzida. Com base nos dados verificados, algumas das hipóteses consideradas foram: a) os profissionais iniciantes, os quais representam uma porção significativa dos respondentes, não se sentem confiantes o suficiente para precificar os seus serviços de modo a atingirem uma renda igual ou superior a um salário mínimo; b) os clientes não estão cumprindo com o pagamento previsto pelos serviços de forma adequada; c) os clientes não estão aprovando os orçamentos oferecidos por estes profissionais, fato que os condiciona a reduzir significativamente o valor cobrado; d) os profissionais sentem-se desencorajados a cobrar um valor justo pelos seus serviços devido a fatores externos à prática.

\section{Principais benefícios em trabalhar como freelancer}

Figura 1 - Benefícios. Fonte: elaborado pela autora.

Mobilidade

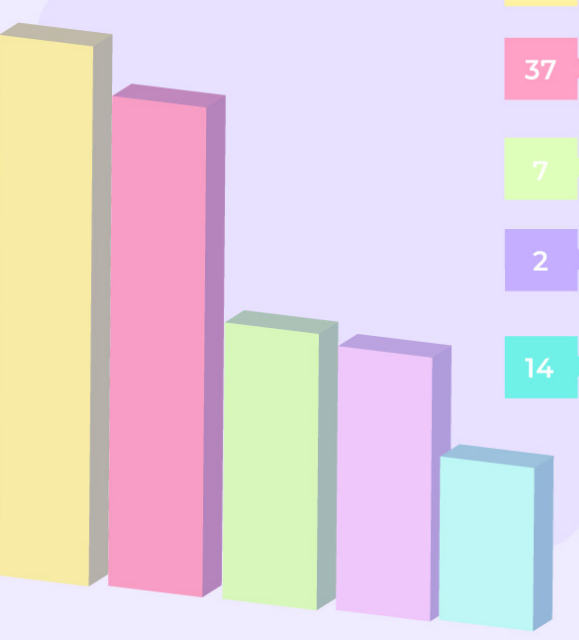

Ter meu próprio negócio modelo de trabalho

Possibilidade de definição do perfil dos clientes/projetos

Relação direta com o cliente

Informalidade 
A partir do questionário foi possível observar as opiniões dos próprios profissionais a respeito das principais vantagens e dificuldades encontradas ao praticar seus serviços em modo freelancer. Como método de preenchimento dessa parte do formulário, foi instruído aos respondentes que escolhessem 3 opções de benefícios e 3 opções de dificuldades encontradas em sua prática. Com base nos dados apresentados na figura 1 , percebe-se que os 4 benefícios mais frequentes foram, respectivamente: mobilidade, ter o seu próprio negócio ou modelo de trabalho; flexibilidade nos horários de trabalho; e possibilidade de definição do perfil de clientes/área de atuação. Quanto às dificuldades (figura 2) o desamparo legal na prestação de serviços como uma das mais proeminentes. Adicionalmente, conforme consta no gráfico a seguir, como quinta resposta mais selecionada, houve o não pagamento pelos serviços por parte do cliente, mais um comportamento que pode ser oriundo da falta de formalização na prestação de serviços.

\section{Principais dificuldades em trabalhar} como freelancer

Conquistar clientes e espaço no mercado

Gerenciamento da atividade

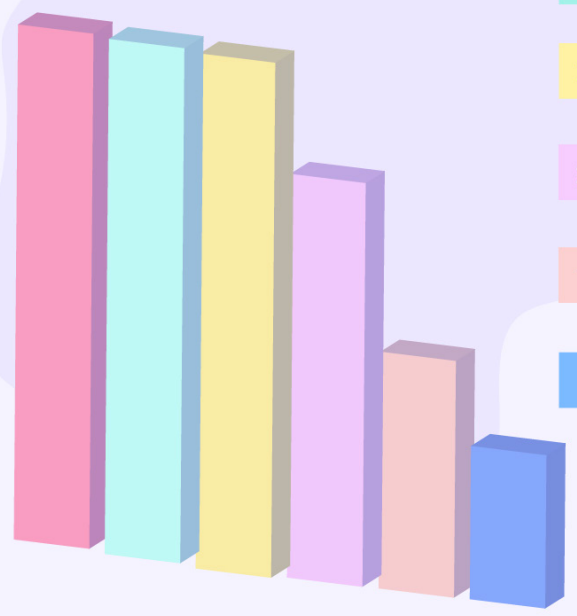

Definir um modelo de preço para os serviços

Desamparo legal da prestação de serviços

Não pagamento pelos serviços

11 Relacionamento com os clientes

Figura 2 - Dificuldades. Fonte: elaborado pela autora. 
Ao considerarmos a independência como característica intrínseca ao trabalho freelancer, é possível elucidar os benefícios e dificuldades citadas como duas faces opostas. Ao mesmo tempo em que os respondentes consideram a criação do próprio modelo de trabalho um fator positivo, estes encontram dificuldade no gerenciamento da atividade. As demais dificuldades também se encontram inseridas no conjunto de elementos que compõem o processo de gerenciamento da prática, como a definição do preço dos serviços e obtenção de clientes - esta última que também se opõe a eleição da vantagem de definição do perfil do cliente. Com exceção do não pagamento pelos serviços, essa dificuldade está associada principalmente ao desamparo legal e à informalidade, a qual foi definida como um dos benefícios da prática freelancer por $23 \%$ dos respondentes.

Quanto à utilização de um termo de compromisso na prestação de serviços, 54\% dos respondentes afirmam utilizar ou já ter utilizado um documento dessa natureza. Destes, $54 \%$ representam 30 respondentes e $46 \%$ formularam o seu documento a partir da adaptação de um modelo encontrado na internet. Quanto aos demais, 26\% formularam sem auxílio, $13 \%$ elaboraram com o auxílio de um colega mais experiente, $10 \%$ com auxílio jurídico e 3\% utilizam um documento formulado exclusivamente por um advogado.

Por outro lado, uma quantidade considerável de respondentes, 45\% afirmaram não utilizar nenhum tipo de termo de compromisso em sua prática. Foi questionado a essas pessoas o motivo pelo qual elas optaram por abdicar de tal documento. Embora apenas uma parcela destes $45 \%$ tenha respondido, foi verificado que os dois motivos mais proeminentes foram: (a) não acharam necessário ou (b) não souberam formular um documento sozinho, ambas as opções exibindo o mesmo número de participantes. O terceiro motivo mais selecionado foi a falta de reflexão sobre o assunto. Desse modo, confirma-se a possibilidade levantada anteriormente neste estudo.

Como etapa final do processo de preenchimento do questionário, foi oferecida uma questão aberta na qual era 
possível relatar as complicações e situações desfavoráveis experienciadas, provenientes da falta de utilização de um termo de compromisso entre profissional e cliente.

A complicação mais frequente nos depoimentos foi em relação ao pagamento pelos serviços. O respondente número 3 afirmou: "A falta de contrato causa falta de comprometimento dos clientes com o pagamento". As ocorrências mais citadas, de uma maneira ou outra, estão atreladas ao pagamento, como o atraso deste e pedidos de alterações no preço cobrado inicialmente.

Sim! Tive problemas quanto a comprovação de falta de pagamento de um serviço que prestei. A cliente em questão não me pagou no final do mês, como "combinado" (bem informalmente, diga-se de passagem) e passou 3 meses sem dar as caras. Após esse período de tempo ela me chama cobrando "serviços pendentes" (que na verdade já haviam sido entregues e NÃO pagos). Não havia outra comprovação se não as conversas (que estavam muito vagas pois o acordo foi feito pessoalmente). Infelizmente, a cliente passou a ignorar minhas mensagens esclarecendo a situação e não tive meios de provar para receber o que ela me deve pelo meu trabalho (RESPONDENTE 5, 2019).

O respondente 9 experienciou atrasos no pagamento e pedidos de alterações no serviço que havia sido entregue 1 mês antes, sem pagamento adicional por parte do cliente por tais alterações.

Não recebi o pagamento no prazo acordado, clientes que sempre queriam pagar mais barato a cada demanda, solicitação de alterações com mais de 1 mês do serviço finalizado/enviado sem pagamento adicional, falta de cumprimento do acordo (no sentido dos materiais que o cliente precisava me enviar para utilizar), ser enrolada por mais de 1 mês negociando e o cliente não fechar nada e nem pagar nada (RESPONDENTE 9, 2019).

O respondente 36 (2019) menciona a falta de um documento de formalização como fator decisivo para a falta de pagamento por parte do cliente. "Já tive problemas com cliente que não me pagou por não ter um documento deformalização". 
Também foi possível verificar depoimentos de participantes que relataram perdas monetárias consideráveis oriundas da falta de amparo contratual. "Sim, por não ter nenhum amparo legal já tomei calotes que vão de 700 reais até 1500 reais por serviços prestados e entregues dentro do prazo" (RESPONDENTE 58, 2019).

Além disso, foram relatadas situações nas quais o cliente não compreendeu o processo de trabalho. Estas situações compreendiam o não entendimento dos itens a serem entregues, número permitido de alterações e mudanças no briefing: "Já, não recebi pelos serviços. Não ficava claro para o cliente o processo do trabalho e o que ele consistia" (RESPONDENTE 4, 2019). Ou seja, essa falta da formalização pode causar dúvidas ao cliente quanto às suas obrigações em relação ao projeto. "Sim, atraso em pagamentos, dúvidas quanto às informações necessárias para finalizar o trabalho e mudanças não previstas de última hora" (RESPONDENTE 26, 2019).

Conforme o relato do Respondente 30 (2019), uma situação recorrente é a quantidade de alterações solicitadas ultrapassar o valor que o profissional atribuiu à sua carga horária de trabalho dedicada à realização do serviço.

Sim, em um dos casos o cliente não realizou o pagamento de uma ilustração. E no outro caso, a cliente pagou conforme solicitado mas pediu inúmeras alterações no projeto, tornando o valor inicial muito baixo perante a quantidade de trabalho e tempo gasto.

Outras situações relatadas foram desistências e abandonos por parte do cliente, ocasiões em que profissionais não obtiveram retorno e pagamento pelo serviço, parcial ou completamente executado. Sobre este tema, o respondente número 14 expõe: "Cliente abandonando a encomenda quando a ilustra já tava pronta, ou querendo voltar atrás no valor combinado (RESPONDENTE 14, 2019)".

No entanto, a possibilidade de desistência também é, segundo o respondente 53 (2019), um fator que causa insegurança nos próprios clientes. 
Já tive problemas por não ter estabelecido uma cláusula de desistência do cliente. Sempre peço de 30 a 50\% de entrada, mas numa dessas peguei um cliente que iniciava os projetos e não finalizava. Então adicionei uma cláusula que na desistência do cliente a entrada paga o trabalho inicial desenvolvido pelo designer. E vice-versa. Pro cliente não se sentir desamparado, na mesma cláusula prevê a devolução da entrada caso haja desistência por parte do designer.

Por fim, observou-se que o termo de compromisso pode servir, segundo o respondente 19 (2019), como uma importante ferramenta em uma possível ação judicial.

Sim, a não formulação de um contrato dificulta que um serviço seja cobrado/executado plenamente, o contratante pode alegar o não conhecimento de algum ponto e devido a não existência de um contato prévio e ser judicialmente notificado se torna mais difícil para ambas as partes.

Portanto, é importante reiterar o objetivo inicial da pesquisa apresentada no presente artigo. Como exposto, objetivou-se com este estudo a compreensão e definição da prática profissional freelancer em design e das possíveis necessidades e dos problemas enfrentados por eles frente à informalidade. Por meio do questionário foi possível verificar contradições no processo de trabalho freelancer, ao passo que essa atividade proporciona uma independência bastante atrativa a muitos profissionais, no entanto a própria independência exige o autogerenciamento da prática. Além disso, com base nas respostas dos entrevistados, ficou clara a dificuldade que muitos profissionais têm de se autogerenciarem e alcançarem resultados satisfatórios com seu trabalho.

No próximo item será abordada a natureza da formalização contratual no âmbito da prestação de serviços, com vistas a compreender os elementos deste documento e conseguir formalizar um modelo que trata da prestação autônoma de serviços em design. 


\section{A FORMALIZAÇÃO DA PRESTAÇÃO DE SERVIÇOS FREELANCER EM DESIGN}

Em tempos atuais, os termos de compromisso servem ao propósito fundamental de assegurar o cumprimento de acordos, respaldando que as transações comerciais ocorram sob determinadas condições (KAPAZ, 2003). De maneira geral, os termos de caráter comercial podem servir a transações de compra e venda de bens e produtos ou de prestação de serviços. Considerando que a prática freelancer se encaixa na segunda categoria, um termo de compromisso desta natureza serve ao propósito de pontuar os aspectos já discutidos e ratificar um acordo entre designer e cliente.

Ao pensar na prestação de serviços em design, é importante considerar o processo de trabalho que a constitui. Segundo Strunck (2010), um bom projeto de design só pode existir mediante à coleta prévia de informações precisas sobre o problema a ser resolvido. Esta coleta deve ser feita a partir de um briefing, o qual consiste em um documento que direciona precisamente cliente e designer para o trabalho a ser realizado (STRUNCK, 2010). Por configurar um guia para o conceito e desenvolvimento do projeto, o briefing deve ser gerado no início do processo, a fim de reunir dados sobre o cliente, projeto, e detalhar todos os componentes e tarefas a serem realizadas. Esta etapa, além de conscientizar o cliente, minimiza possíveis riscos para o designer (BELTRÃO, 2010).

Após o preenchimento do briefing, o qual deve ser lido e aprovado pelo cliente, inicia-se o processo de criação da proposta de trabalho. Nesse contexto, a proposta passa a configurar um termo de compromisso a partir do momento que esta é assinada por ambas as partes envolvidas (BELTRÃO, 2010). Desse modo, podemos entender o termo de compromisso como um documento que reúne os componentes do projeto, prazos a serem cumpridos para cada etapa, honorários e formas de pagamento a serem praticados (STRUNCK, 2010). Esta proposta deve, enfim, ser aprovada e assinada pelo designer e pelo cliente. 
Assim sendo, os componentes do termo devem ser cuidadosamente pensados pelo profissional, a fim de evitar desentendimentos e a negligência de aspectos importantes ao serviço prestado. Para delinear os componentes da proposta ideal, este estudo utilizou como referência as obras de Strunck (2010) e Beltrão (2010), os quais detalham os aspectos fundamentais.

Primeiramente foi analisado o modelo apresentado no livro “Viver de Design” de Gilberto Strunck (2010). Nele, o autor oferece um roteiro com 7 itens que devem compor um plano de trabalho completo:

1. Local e data: neste primeiro item o profissional deve informar o destinatário do documento, sendo empresa ou pessoa física, endereçamento completo e data de apresentação do documento.

2. Apresentação do projeto: aqui deve-se apresentar, de forma sucinta, o objetivo que se espera atingir com o projeto, o que será apresentado ao fim da prestação de serviços e quaisquer benefícios que o cliente obterá com o projeto.

3. Lista de serviços: neste item o autor recomenda que se especifique as etapas do projeto e quais peças serão entregues em cada uma. Este item é subdividido em etapas, as quais configuram a geração de ideias e conceitos para possíveis soluções para o problema a ser resolvido com a apresentação de um ou mais conceitos visuais para o cliente visualizar, o anteprojeto com um layout mais bem detalhado que ofereça uma ideia tangível do projeto final à ser entregue e o projeto final com especificações técnicas para a produção do serviço contratado. 
4. Serviços excluídos pela proposta: neste item devem ser explicitados com clareza os serviços que não serão fornecidos ao cliente, como fornecimento de textos, fotos e impressões.

5. Prazos para o cumprimento de cada etapa: o autor recomenda que os prazos sejam especificados de acordo com as etapas apresentadas no terceiro item.

6. Honorários e forma de pagamento: aqui deve-se especificar o valor a ser cobrado pelo serviço. $O$ autor recomenda que se cobre uma porcentagem de $20 \%$ ou $30 \%$ antes da entrega do projeto finalizado. Também deve ser especificado o prazo que o cliente terá para realizar o pagamento, além de quaisquer multas e juros a serem cobrados em caso de atraso no pagamento.

7. Condições gerais: Neste item devem ser expostos quaisquer condições adicionais como às que dizem respeito aos direitos autorais - itens, tiragens, prazos, entre outros - cláusulas de confidencialidade da parte do profissional, validade dos preços apresentados e validade da proposta apresentada.

André Beltrão, em seu livro "Quanto custa meu design?" (2010), propõe um modelo mais sucinto, com 4 itens ao todo: Endereçamento e apresentação, custo, cronograma e condições gerais.

$\mathrm{O}$ item endereçamento e apresentação compreende aspectos que, no modelo de Strunck (2010), possuíam categorias próprias, como a delimitação de tarefas e a especificação de quais serviços não serão fornecidos ao cliente. O segundo item, custo, configura a lista de peças e a precificação a ser aplicada à cada uma delas. No terceiro, o cronograma, o autor recomenda que se especifique a quantidade de dias que serão dedicados 
à execução de cada etapa do trabalho, oferecendo ao cliente. No quarto e último item, as condições gerais, deve-se expor ao cliente quaisquer garantias e condições que o profissional julgar necessárias para a execução do projeto. O autor recomenda cláusulas como multas em caso de atraso de pagamento e desistência, taxas não inclusas no orçamento, e prazo de validade da proposta. Assim como Strunck (2010), Beltrão (2010) orienta que se exija a assinatura do cliente como modo de implicar a aceitação dos termos apresentados, deste modo, configurando o documento em um contrato de prestação de serviços.

É indispensável que seu cliente assine aqui aprovando a proposta, ou pelo menos envie um e-mail em resposta ao seu dizendo claramente que a proposta "tal "está aprovada. Em algumas empresas o funcionário não está autorizado a assinar contratos, uma aprovação formal por e-mail também serve (BELTRÃO, 2010).

A análise dos modelos de propostas de trabalho e termos de compromisso estruturadas por ambos os autores serviu ao propósito de concretizar a configuração de um termo de compromisso ideal para um profissional da área do design. A partir do cruzamento e emprego dos elementos apresentados como indispensáveis, como etapas de trabalho, itens a serem entregues e incorporação do recurso briefing, foi possível formular um modelo de trabalho moldado ao fluxo projetual característico do design.

\section{TERMO DE COMPROMISSO PARA 0 DESIGNER FREELANCER}

Como base para a criação do modelo de termo de compromisso foi utilizado o modelo de Strunck (2010), por ser mais completo e abrangente em suas cláusulas. Além dos aspectos já citados, foram adicionadas cláusulas que abrangem o número de alterações às quais o cliente tem direito e os casos de desistência por parte do cliente ou profissional. Levando em conta que este termo de compromisso tem por finalidade amparar a presta- 
ção de serviços em design, considerou-se importante oferecer neste um espaço para que o designer explique as intenções e objetivos que deseja atingir com o projeto e a segmentação do processo de trabalho em etapas (as quais foram utilizadas na elaboração do cronograma). No mais, o modelo de termo de compromisso que é apresentado a seguir teve por principal objetivo elucidar para o cliente o processo de trabalho do designer, destacar os serviços a serem oferecidos na transação comercial e assegurar que o cliente compreenda essa prestação.

Para fins de demonstração foram utilizados nomes e números de documentos fictícios, gerados aleatoriamente por uma ferramenta disponível no site 4 devs ${ }^{[7]}$. Igualmente, como situação exemplar para o esboço de uma proposta de serviço, foi selecionada a criação de uma identidade visual.

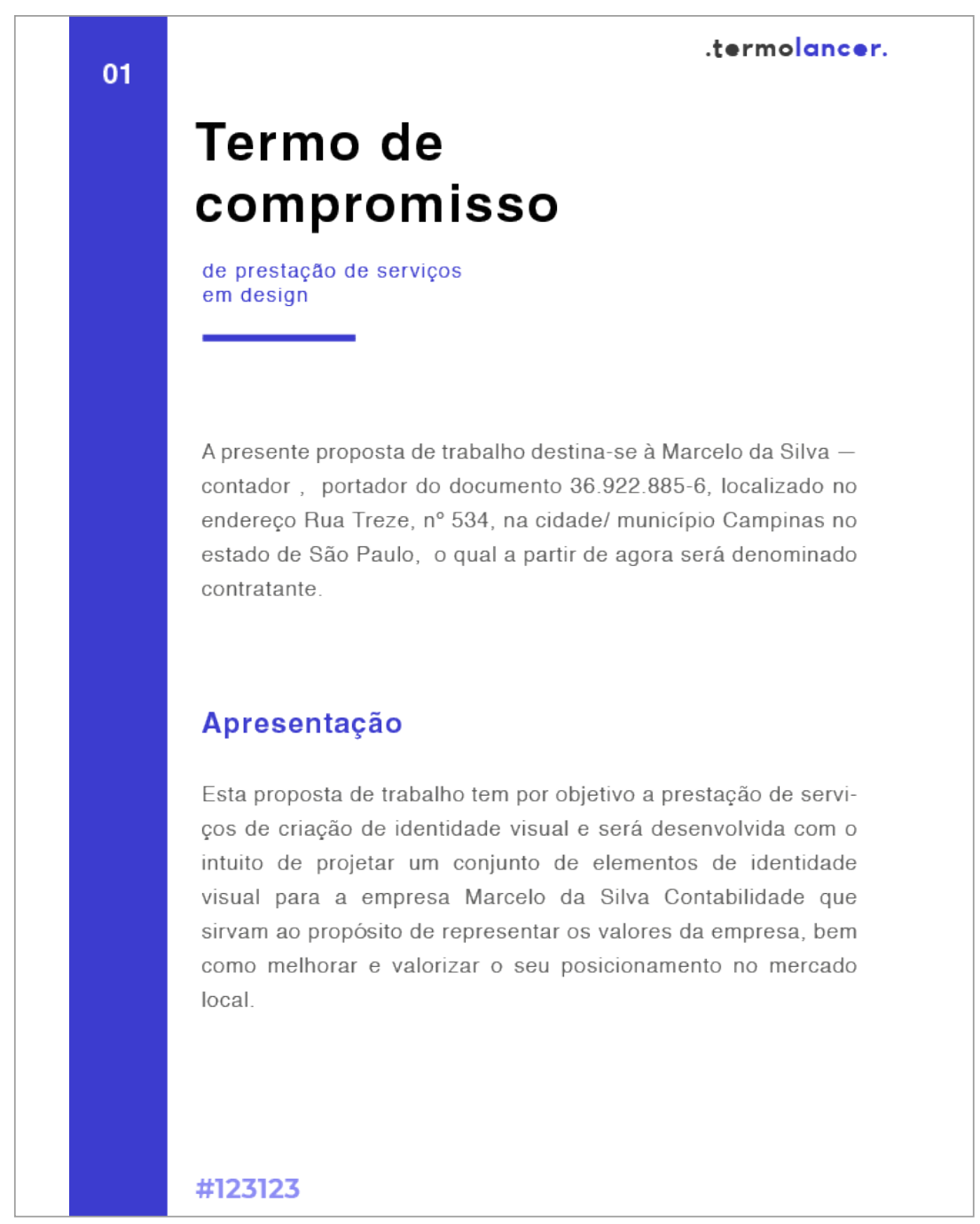

[7] O site 4devs.com.br oferece ferramentas úteis para programadores, analistas e testadores de softwares. A ferramenta utilizada para esta etapa foi a geradora de $\mathrm{CPF}$ e pessoas fictícias. 
+ Realização do benchmarking de empresas similares com o intuito de fazer um levantamento das estratégias e dos elementos visuais utilizados por empresas do mesmo segmento de atuação.

+ Definição do conceito a ser trabalhado e consequente estratégia gráfica adotada, comoa escolha das formas, paleta de cores e tipografias

+ Esboços da marca

+ Finalização da proposta.

+ Criação do material de papelaria básica oficial da empresa (conforme especificação abaixo)

+ Criação de mockups para os layouts

+ Criação do manual de identidade visual.

Lista de serviços à serem entregues:

+ Marca

+ Materiais de papelaria: Cartão de visitas; Papel Timbrado,

\section{Alterações}

Esta proposta prevê uma quantidade máxima de alterações por etapa, a qual consiste em 2 alterações. Para cada alteração solicitada serão acrescentados 5 dias úteis para o cumprimento da alteração e início da próxima etapa. Quaisquer alterações além do número previsto terão um custo de 70 reais - setenta reais.

Após a finalização e aprovação do projeto não serão realizadas novas alterações

\section{Investimento}

O investimento total para a realização deste serviço é de 1000 reais - Mil reais. O pagamento deste serviço será dividido em duas parcelas. A primeira parcela equivale à $30 \%$ do valor total, ou seja, 300 reais - Trezentos reais. Esta parcela deve ser paga em até 15 dias úteis após a data de assinatura desta proposta. É importante salientar que a execução do serviço contratado iniciará somente mediante o pagamento deste valor inicial.

\section{+ Manual de identidade visual encadernado}

Serviços que não serão entregues:

+ Banners, placas e afins

+ Slogans

+ Modelos de posts para redes sociais

\section{Cronograma}

Estima-se que o trabalho será entregue em sua totalidade em 60 dias úteis, os quais serão divididos nas seguintes etapas:

\begin{tabular}{ll} 
Etapa 1 & 5 dias úteis \\
\hline Etapa 2 & 10 dias úteis \\
\hline Etapa 3 & 15 dias úteis \\
\hline Etapa 4 & 10 dias úteis \\
\hline Etapa 5 & 5 dias úteis \\
\hline Etapa 6 & 5 dias úteis \\
\hline Etapa 7 & 10 dias úteis
\end{tabular}

\#123123

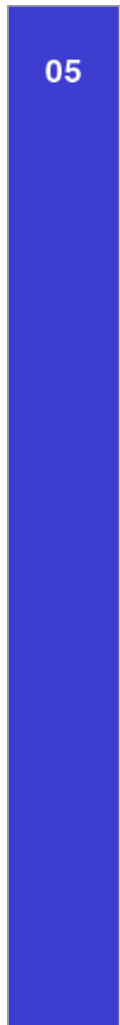

termolancer

Os pagamentos devem ser realizados diretamente à Mariana Ribeiro ou por depósito/transferência bancária

Dados da conta para transferência bancária

Nome: Mariana Ribeiro

Agência: 000000

Conta: 000000

Cpf: 0000000

O atraso no pagamento resultará em uma multa proporcional à $10 \%$ do valor total por dia útil de atraso.

O não pagamento do valor total resultará na suspensão dos serviços realizados pelo contratado, sem aviso prévio.

A desistência por parte do contratante após o início das atividades do contratado resultará em uma multa de $20 \%$ do valor total, a qual deverá ser paga em até 5 dias úteis após a notificação formal de desistência por e-mail, sem exceções.

Em caso de desistência da prestação de serviços por parte do contratado, quaisquer valores pagos serão ressarcidos ao contratante em até 5 dias úteis após a notificação formal de desistência por e-mail. 
Figuras 3, 4, 5, 6, 7 e 8 (páginas anteriores) - Layout das páginas $1,2,3,4,5$ e 6 (respectivamente),

\section{Condições gerais}

O contratado se compromete a não revelar, reproduzir, utilizar ou dar conhecimento, em hipótese alguma, a terceiros, de dados, informações ou materiais obtidos com sua participação, sem a prévia análise do contratante

Todos os conteúdos gerados durante o trabalho do contratado são da posse do contratante somente mediante o pagamento integral pelo serviço prestado, sem exceções.

A presente proposta tem validade de 30 dias úteis

Assinam abaixo as partes estando de acordo com os termos desta proposta de fornecimento de serviços: do modelo termo de compromisso. Fonte: Elaborado pela autora.

Mariana Ribeiro, portadora do documento 00000000

Marcelo da Silva

Pelotas, 13/11/2019

Conclui-se aqui a apresentação do modelo de termo de compromisso elaborado com base nos componentes que Gilberto Strunck (2010) expôs como essenciais em seu livro. Sendo assim, este modelo tem por objetivo representar um exemplo concreto para melhor visualização das cláusulas mencionadas e a organização destes elementos. 


\section{CONSIDERAÇÕES FINAIS}

A pesquisa aqui apresentada foi instigada pela experiência pessoal da autora como designer freelancer e os empecilhos e complicações que, ao seu ver, poderiam ter sido evitados por intermédio de um documento de formalização da prestação de serviços. Existem poucos estudos que contemplem a prática de design como freelancer no Brasil, o que embora tenha tornado a tarefa de conceituar esta pesquisa um desafio ainda maior, legitima a necessidade de um estudo desta natureza.

Embora a motivação inicial para o tema desta pesquisa tenha sido em grande parte empírica, tendo em vista a vivência da autora e de seus colegas de profissão, o delineamento das demais problemáticas aqui apresentadas através de autores, mostrou-se uma base substancial para o aprofundamento deste estudo, pois foi possível levantar questionamentos acerca da dificuldade em se estabelecer no mercado como profissional, em autogerir o trabalho e a falta de seguridades (como plano de saúde, licença maternidade ou férias remuneradas).

Dessa forma, teve-se o objetivo não apenas de conceituar o campo de trabalho freelancer, mas também identificar as pessoas que o compõem. Através do espaço para o envio de depoimentos disponibilizado no questionário, pretendeu-se oferecer a essas pessoas um espaço de expressão, ainda que anônima, das suas dificuldades e complicações encontradas ao longo de sua prática profissional.

Concluída esta explanação, buscou-se por intermédio da análise das obras de Strunck (2010) e Beltrão (2010), a construção de uma base para a elaboração um modelo de termo de compromisso que se adequasse não apenas a profissionais freelancers como um todo, mas especificamente a designers, uma vez que foram expostos os elementos necessários à criação de uma proposta de serviço para essa área - como lista de peças, lista de itens não fornecidos e etapas do trabalho. Busca-se, assim, por meio da organização e exposição destes parâmetros, esclarecer quais elementos são importantes a se- 
rem considerados ao formular um documento dessa natureza. Por fim, apresentou-se o modelo de termo de compromisso, o qual incorpora as cláusulas expostas por Strunck (2010) e pretende representar uma estrutura concreta, sintetizando alguns aspectos do estudo e servindo como exemplo para os designers freelancers. Este modelo foi criado como parte da prática do Trabalho de Conclusão de Curso, o qual apresentou, adicionalmente, um protótipo ${ }^{[8]}$ de plataforma on-line que permitiria a customização com os dados particulares de cada usuário, do serviço específico a ser prestado e os dados de seu cliente.

Por fim, reitera-se que os resultados e discussões apre-

[8] Disponível em: $<$ https://xd.adobe.com/ view/39aca488-9e114b2c-68ad-b1b9439f33bb$4 \mathrm{fgd} /$ ?fullscreen\&hints=on> sentadas poderão servir como alavanca para estudos posteriores deste objeto de pesquisa tão escassamente explorado.

\section{REFERÊNCIAS BIBLIOGRÁFICAS}

BELTRÃO, André. Manual do freela: quanto custa o meu design? Gestão financeira para freelancers. Rio de Janeiro: 2AB, 2010.

BIAZZI, Renato, LUQUET, Mara. Quantidade de freelancers cresce no momento de crise e desemprego. Jornal da Globo. Disponível em: <https:// glo.bo/36WvK1v>. Acesso em: 21 Nov. 2020.

CAMPOS, Daniel. Complexidade no Design: onde reside e porque grandes marcas são simples. Medium. Disponível em: <https://bit.ly/3fohoLm>. Acesso em: 5 Nov. 2020.

GASPARINI, Claudia. 0 passo a passo para trabalhar como freelancer pela $1^{\text {a }}$ vez. 2017. Disponível em: <https://bit.ly/3pPAyyn> Acesso em: 31. Out. 2019.

GREGG, Melissa. Work's Intimacy. Cambridge:

Polity Press, 2011. Disponível em:<https://bit. ly/3nLTVXj> Acesso em: 20 out. 2019. 
HONG, Kevin; PAVLOU, Paul. Online Labor Markets: An

Informal "Freelancer Economy." Institute for Business

and Information Technology (IBIT). Disponível em:

<https://bit.ly/3360MkS>. Acesso em: 21 Nov. 2020.

KAPAZ, Ronald et al. $\mathbf{O}$ valor do design: guia ADG

Brasil de prática profissional do designer gráfico.

São Paulo: Editora Senac São Paulo, 2003.

LANDOLFI, Fernanda; BERNARDO, Kelen. O Trabalho

Remoto/homeoffice No Contexto Da Pandemia

Covid-19: Um Olhar Para O Setor Educacional. Curitiba:

Universidade Federal do Paraná, Grupo de Estudos Trabalho

e Sociedade, 2020. Disponível em: <https://bit.ly/339fhpw>.

LAUBACHER, Robert; MALONE, Thomas. The

Dawn of the E-Lance Economy. Harvard

Business Review, 1998. Disponível em: <https://

bit.ly/3fnRmYu> Acesso em: 20 out. 2019.

MARCONI, Marina de Andrade. Técnicas de pesquisa:

planejamento e execução de pesquisas, amostragens

e técnicas de pesquisa, elaboração, análise e

interpretação de dados. 3 ed. São Paulo: Atlas, 1996.u

PINHEIRO, Paula. Freelancer: o que é e TUDO que você

precisa saber para ser um, Rock Content, 2018. Disponível

em: <https://bit.ly/3qneNq6> Acesso em: 2 Dec. 2020.

ROCK CONTENT. Mercado Freelancer. 2019. Disponível

em: <https://bit.ly/3flM4N6>. Acesso em: 22 Nov. 2020.

SCHOLZ, Trebor. Digital Labor: The internet as

playground and factory. Nova lorque: Routledge, 2013.

STRUNCK, Gilberto. Viver de design. 6

ed. Rio de Janeiro: 2AB, 2010. 